\title{
Scratch Collapse Test: a new clinical test for peripheral nerve compression
}

\author{
Scratch Collapse Test: um novo teste clínico para nervos periféricos comprimidos \\ Carlos Eduardo Vervloet Sollero, Péricles Maranhão-Filho
}

A 70-year-old woman presented left hand neuropathic pain and nocturnal paresthetic brachialgia. The neurological examination was unremarkable except for positive Scratch Collapse Test (SCT) suggesting left Carpal Tunnel Syndrome (CTS) (Figure). Subsequent electromyographic evaluation was consistent with left CTS. The SCT is a new clinical maneuver for peripheral nerve compression diagnosis $^{1}$ that has greater sensitivity than both Tinel's test and the flexion/nerve compression test for the median and ulnar nerves, respectively. It is believed that a silent period following cutaneous stimuli over the compressed nerve briefly inhibits external shoulder rotation, thus producing the sign which can be indefinitely repeated ${ }^{2}$.
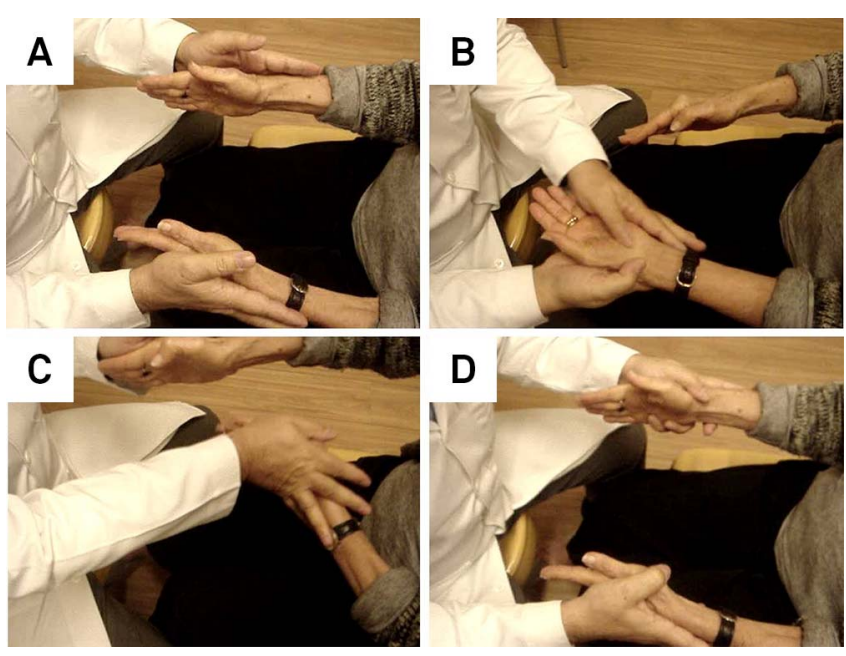

Figure. (A) The patient faces the examiner, elbows flexed and hands neutral. The examiner pushes the patient's forearms, asking them to resist, (B) then "scratches" the skin over the carpal tunnel, and repeats the first step; (C) A positive response is a temporary loss of external resistance with arm "collapse"; and (D) Immediate repetition will show strength recovery.
1. Cheng CJ, Mackinnon-Patterson B, Beck JL, Mackinnon SE. Scratch collapse test for evaluation of carpal and cubital tunnel syndrome. J Hand Surg Am. 2008;33(9):1518-24. http://dx.doi.org/10.1016/j. jhsa.2008.05.022
Logigian EL, Plotkin GM, Shefner JM. The cutaneous silent period is mediated by spinal inhibitory reflex. Muscle Nerve. 1999;22:467-72. http://dx.doi.org/10.1002/(SICI)1097-4598(199904)22:43.0.CO;2-Y

Departamento de Neurologia, Hospital Universitário Clementino Fraga Filho, Universidade Federal do Rio de Janeiro, Rio de Janeiro RJ, Brazil. Correspondence: Carlos Eduardo Vervloet Sollero; Av. Brigadeiro Trompowiski, s/n; 21941-590 Rio de Janeiro RJ, Brasil; E-mail: cesollero@gmail.com Conflict of interest: There is no conflict of interest to declare.

Received 01 August 2014; Received in final form 23 August 2014; Accepted 11 September 2014. 